Supplement of

\title{
On the simultaneous deployment of two single-particle mass spectrometers at an urban background and a roadside site during SAPUSS
}

Manuel Dall'Osto et al.

Correspondence to: Manuel Dall’Osto (dallosto@icm.csic.es)

The copyright of individual parts of the supplement might differ from the CC-BY 3.0 licence. 


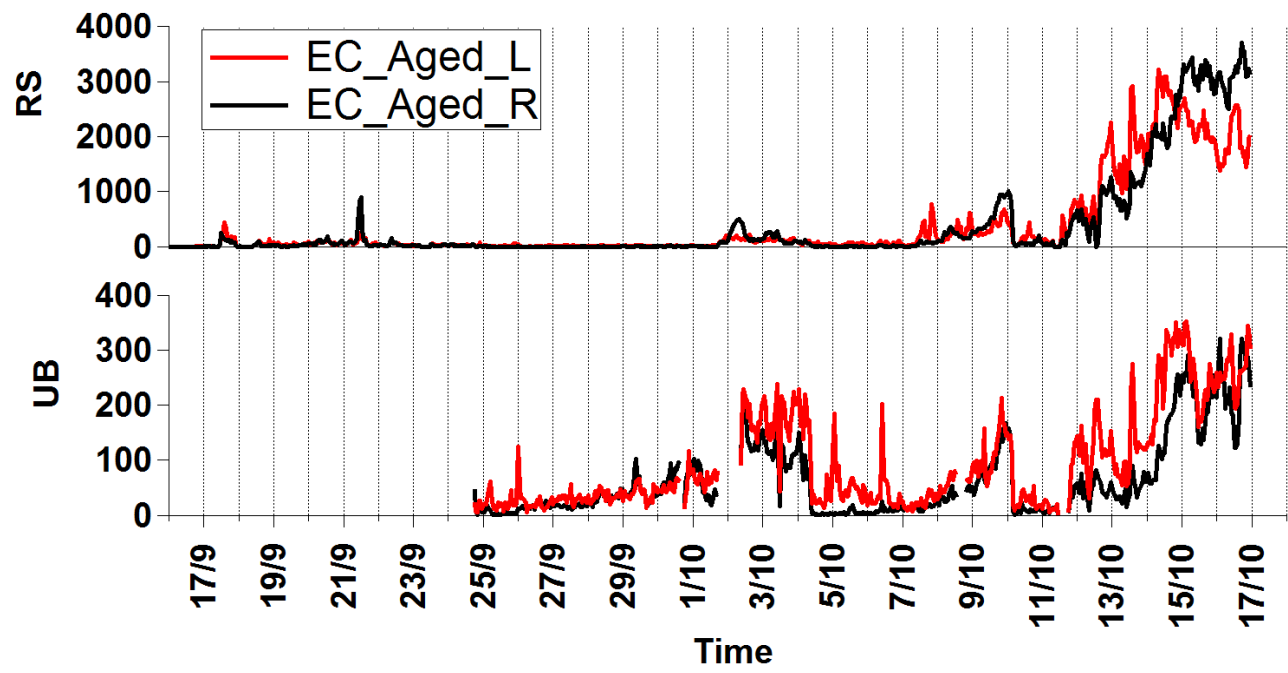

(a)

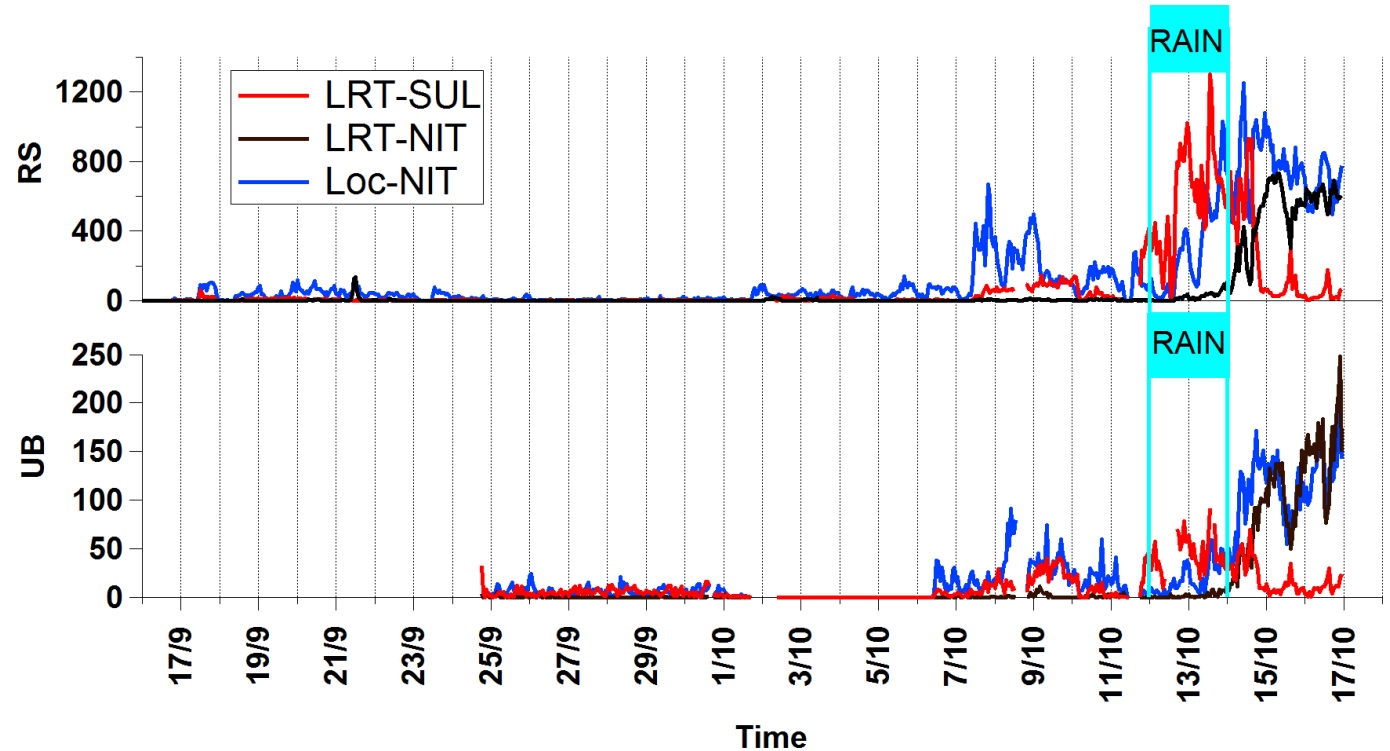

7

(b)

8 


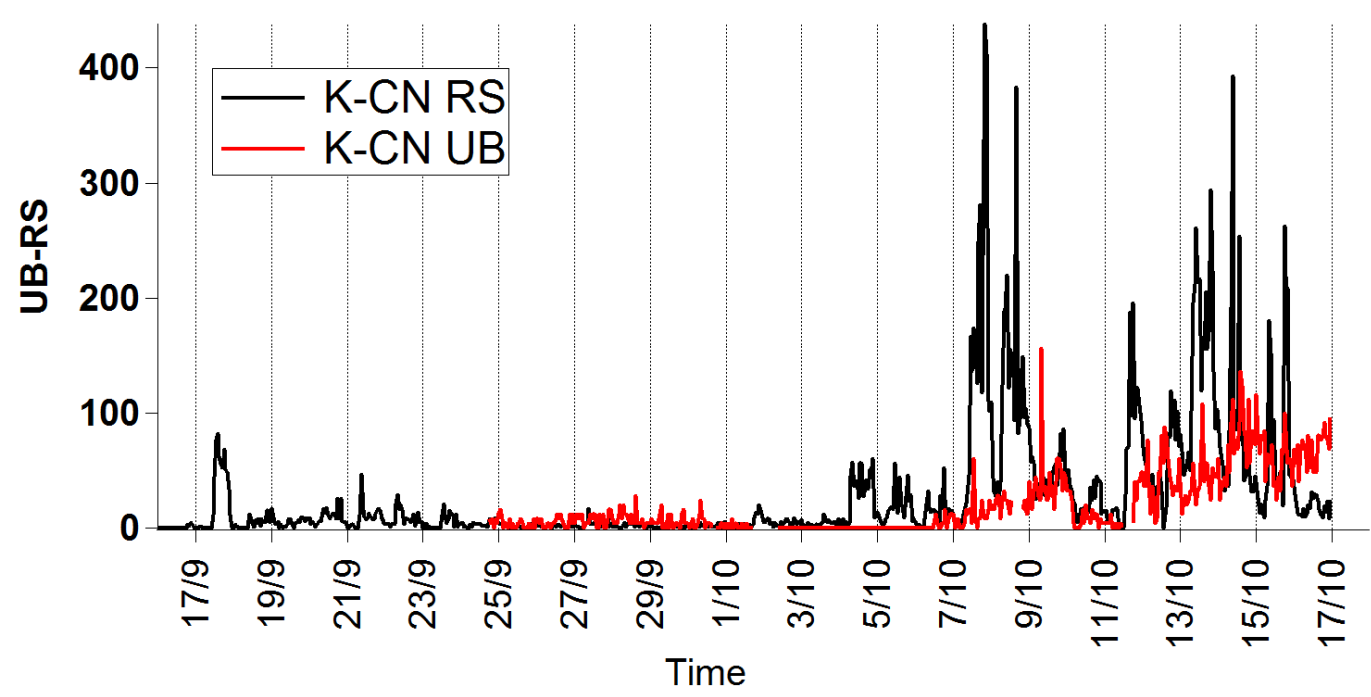

(c)
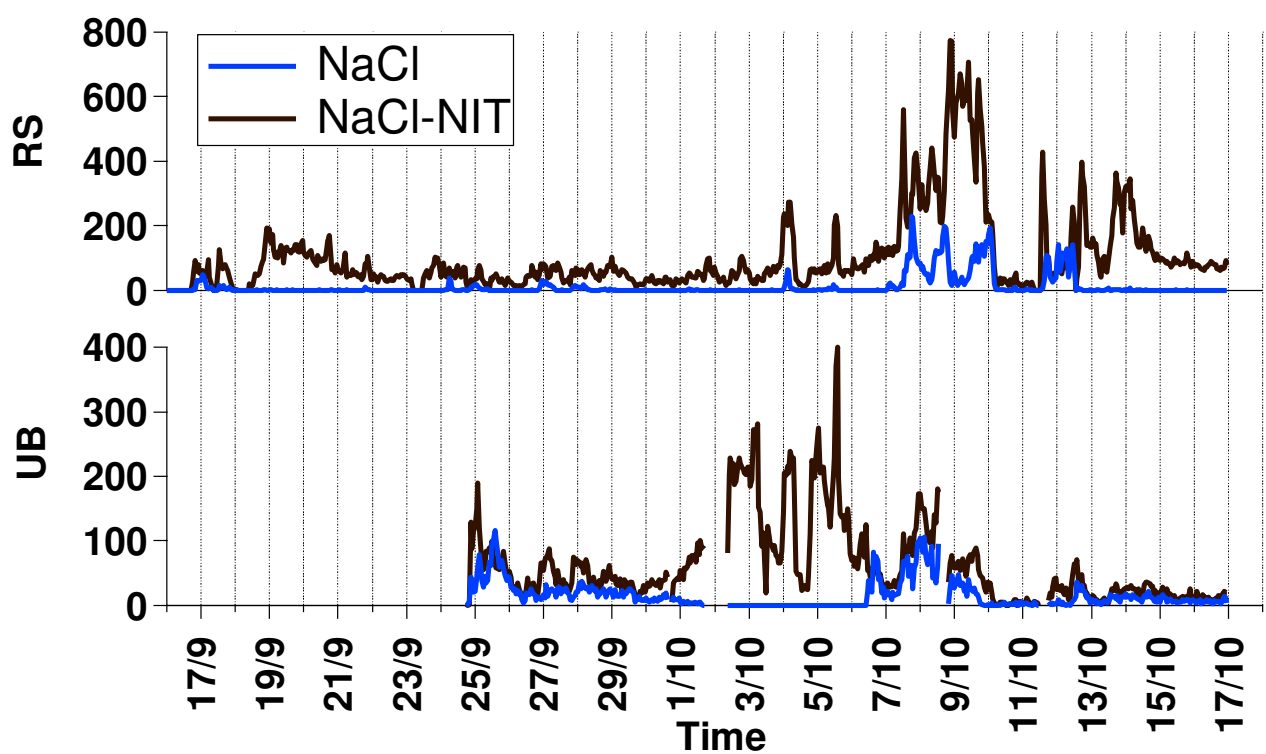

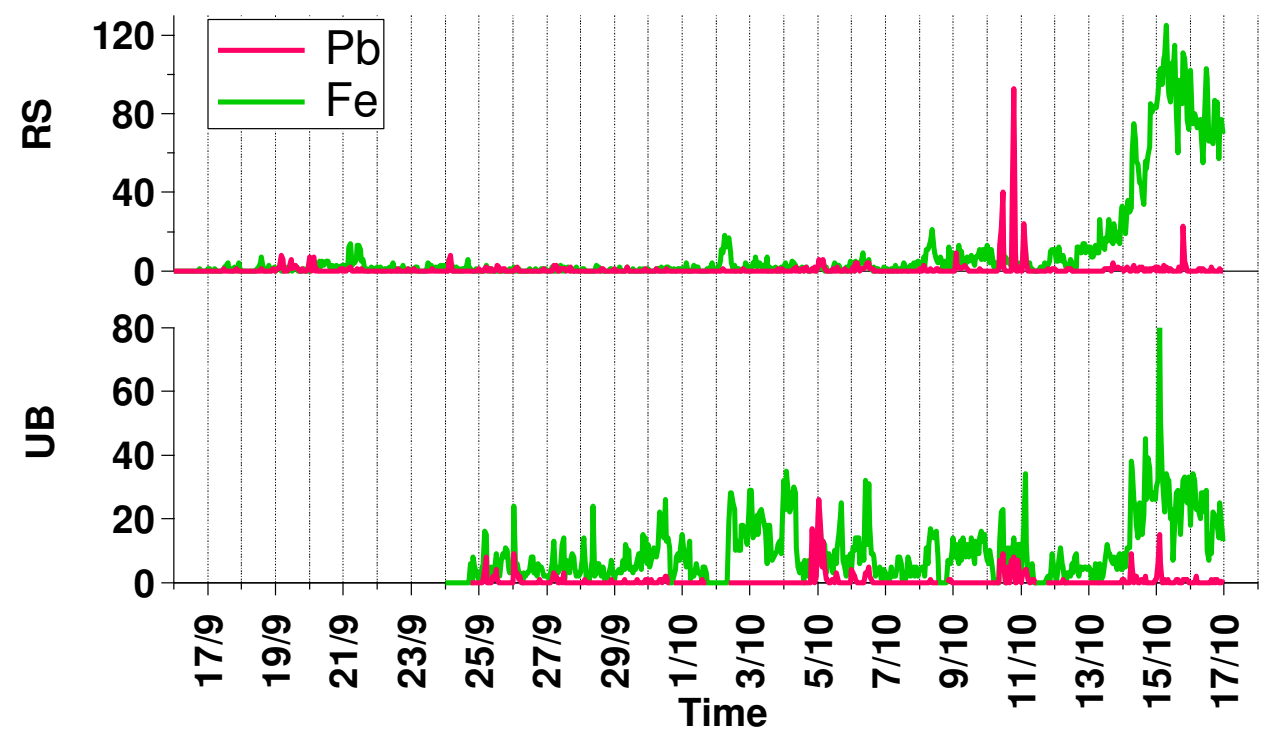

3

(e)

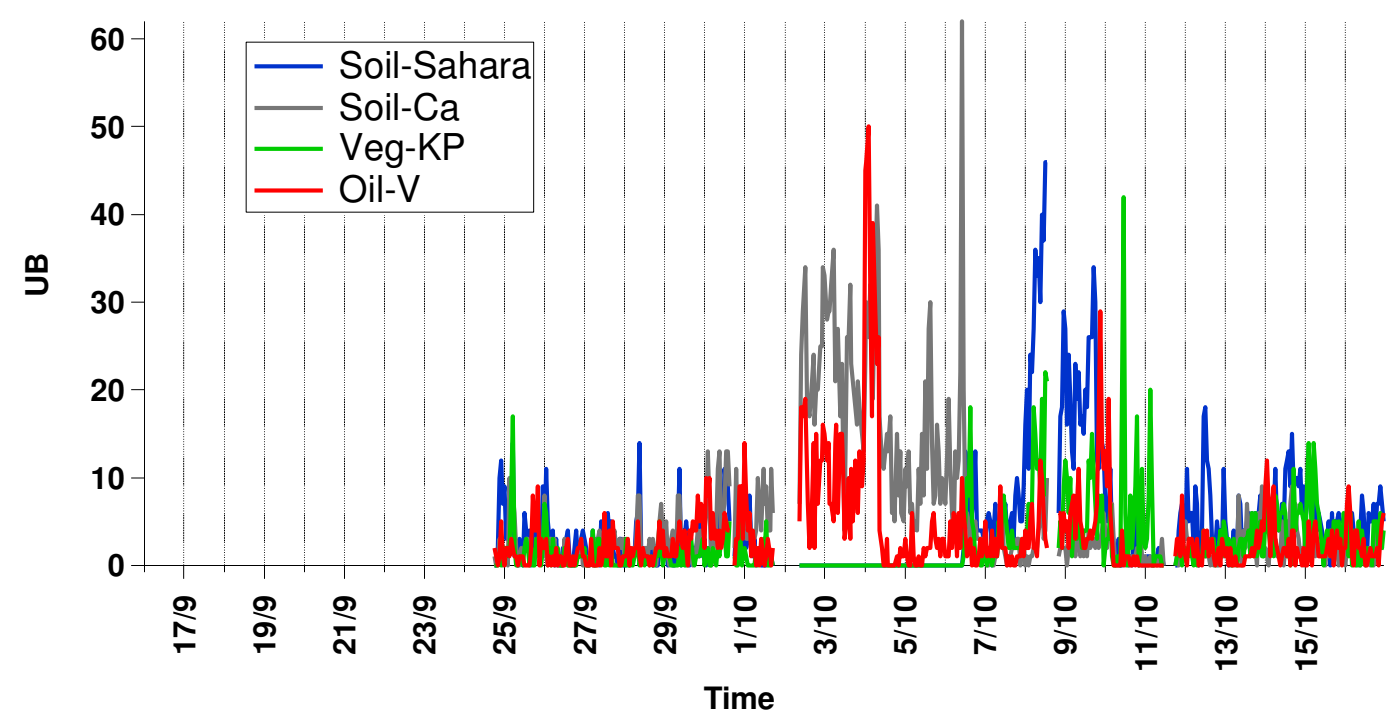

\section{5}

6 

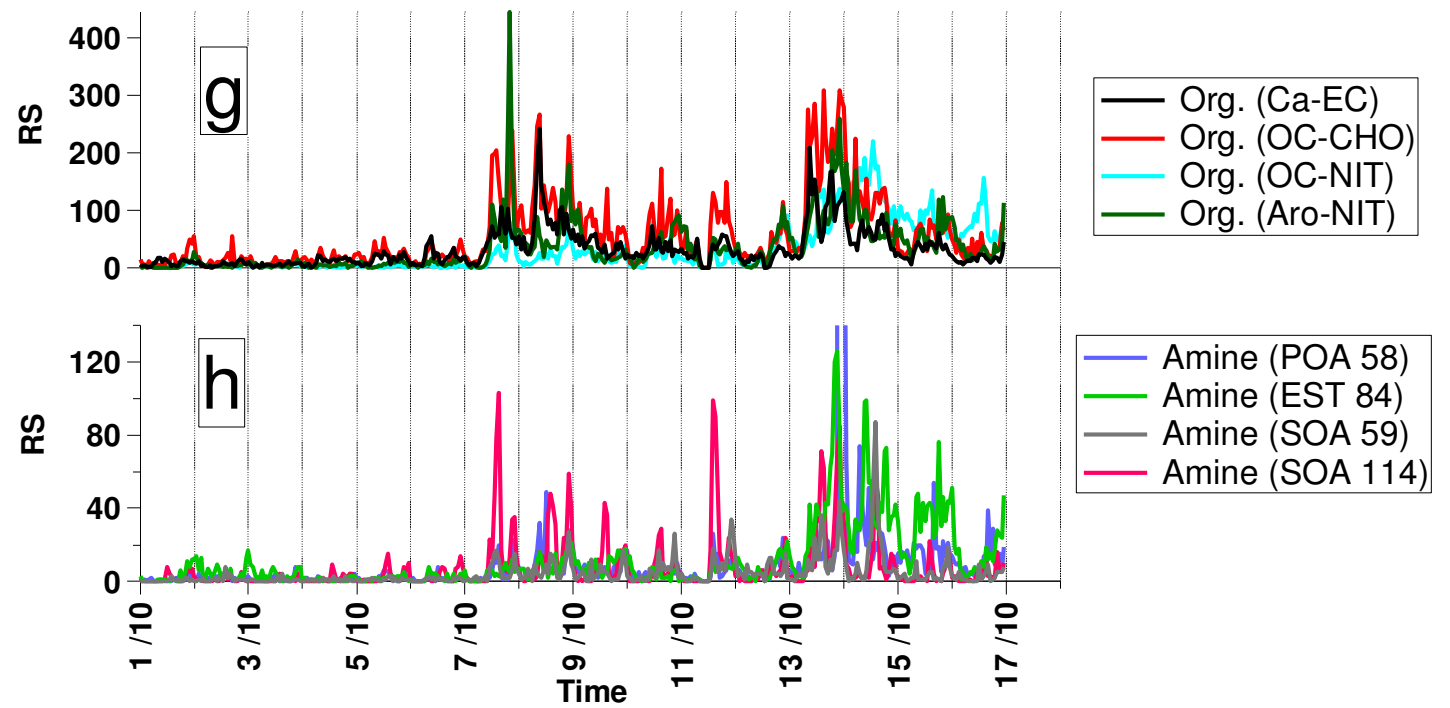

1

$(g, h)$

5 Figure SI 1. Temporal trends of ATOFMS particle types

6

7

8

9

10

11

12

13

14

15 

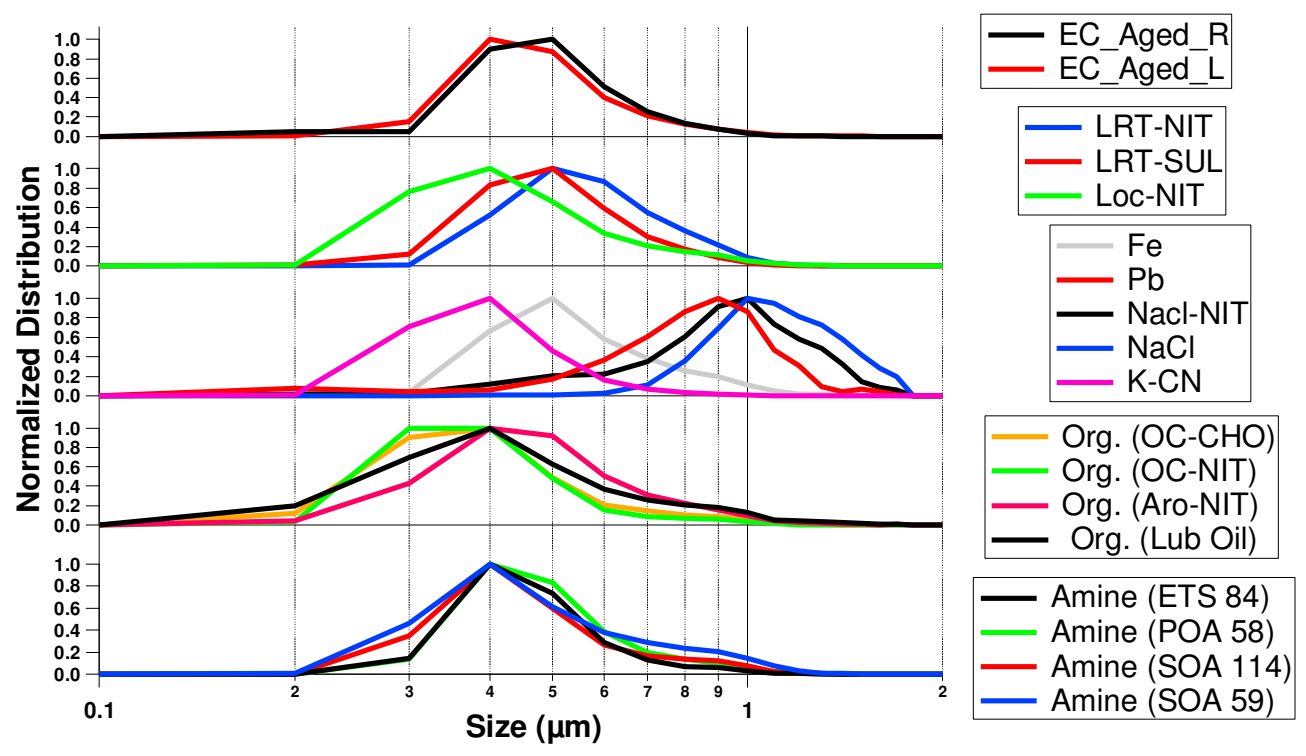

(a)

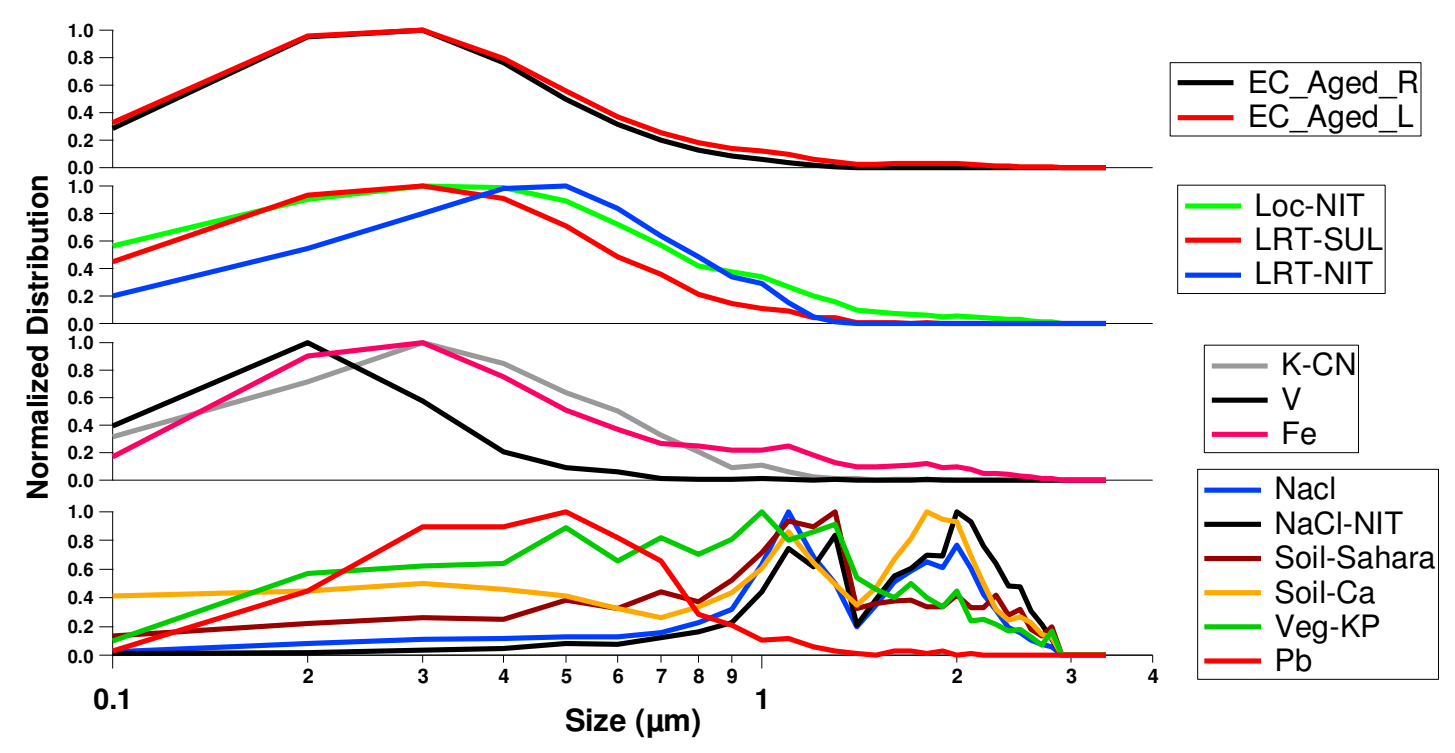

7 SI 2. Aerodynamic size ATOFMS modes for ATOFMS at RS (a) and UB (b) 


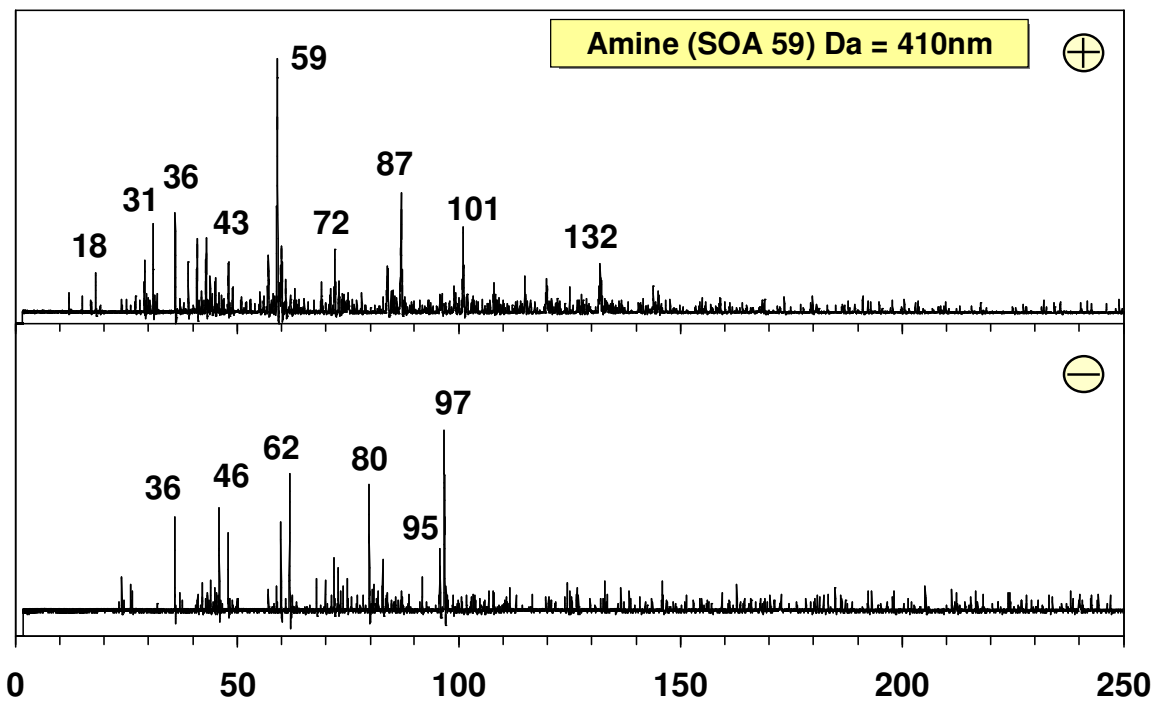

1

2 (a) Amine (SOA 59)

3

4
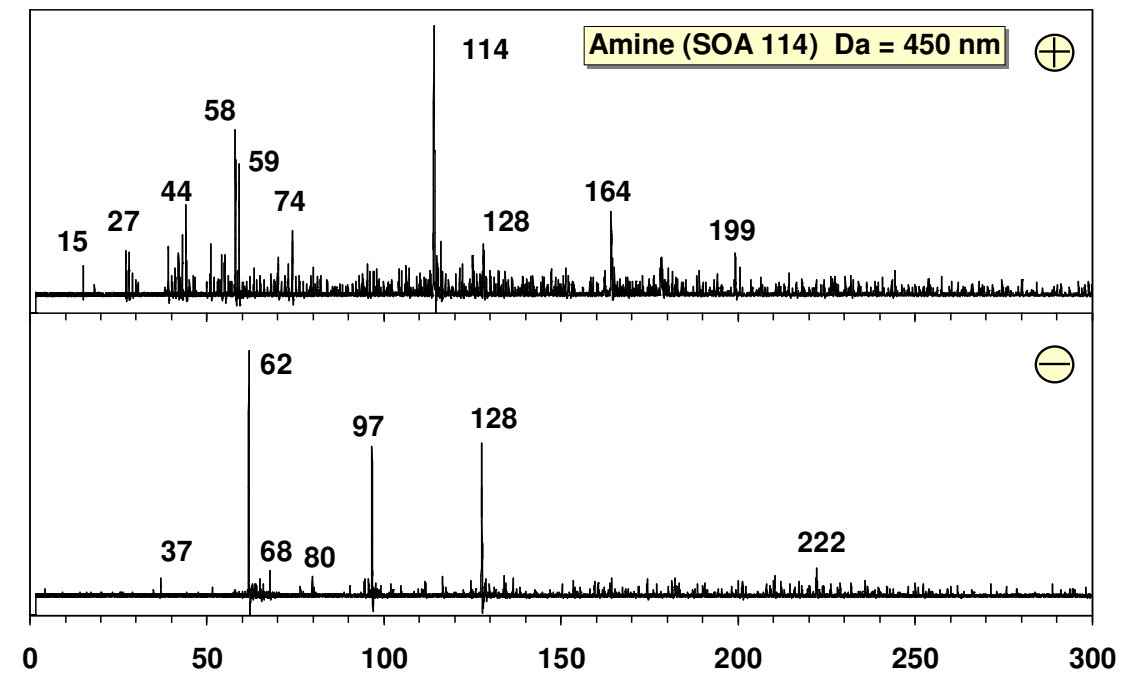

5 (b) Amine (SOA 114)

6

7 


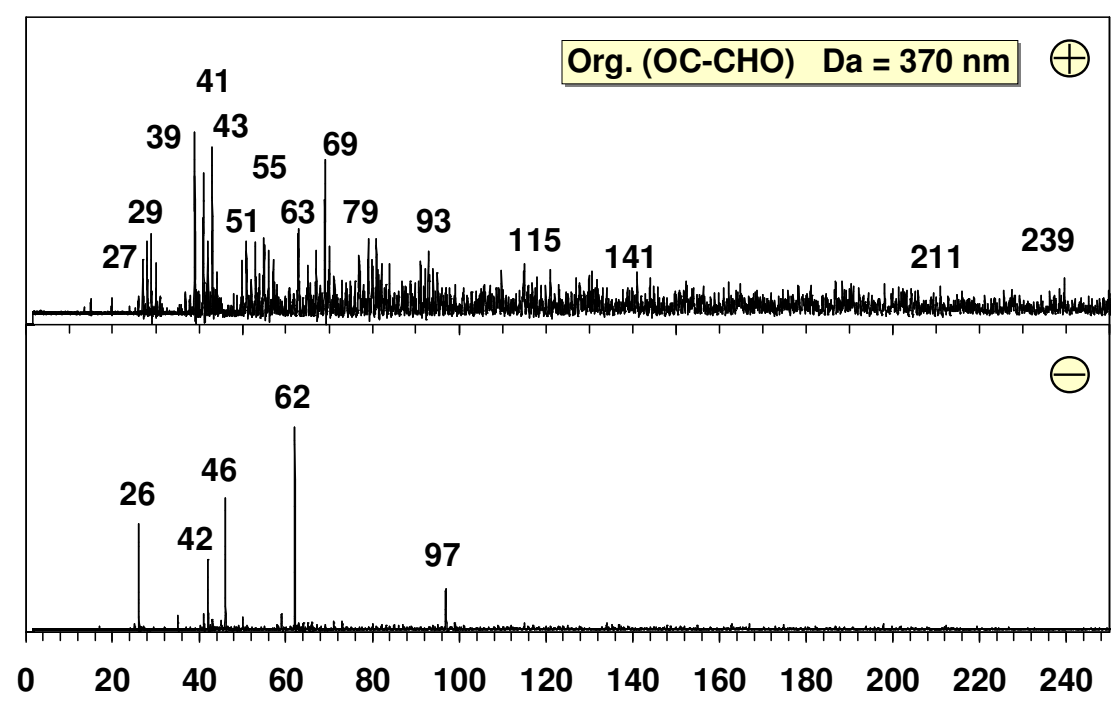

3 (c) Org. (OC-CHO)

4

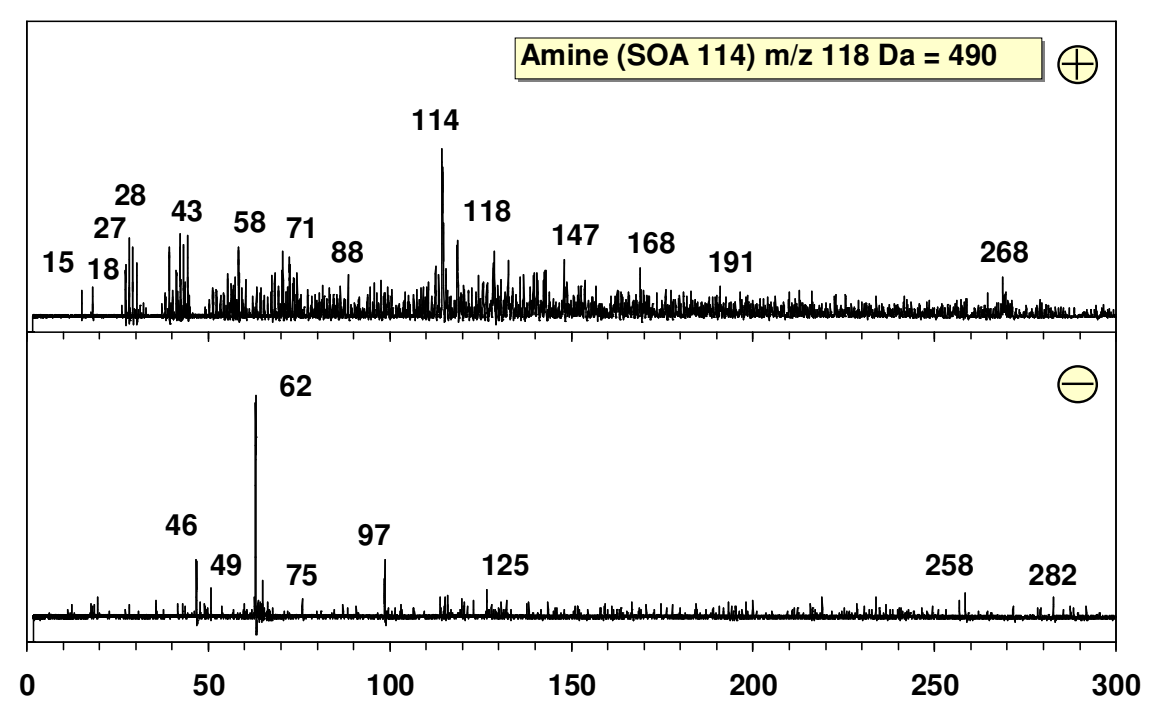

5 (d) Amine (SOA 114) with $\mathrm{m} / \mathrm{z} 118$

6

7 SI 3 a-d: Single particle mass spectra of selected ATOFMS particle types 